\title{
Review: several techniques optimise oxygenation during suctioning of patients
}

\author{
Brooks D, Anderson CM, Carter MA, et al. Clinical practice guidelines for suctioning the airway of the intubated and \\ nonintubated patient. Can Respir J 2001 May;8:163-81.
}

\section{Data sources}

Published, English language studies were identified by searching Medline (1966-98), EMBASE/Excerpta Medica (1974-96), and CINAHL (1982-97) using the search terms trachea, pharynx, tracheostomy, suction, artificial airway, inflation, and endotracheal, and by searching the Cochrane Library. Bibliographies of retrieved studies were reviewed.

\section{Study selection}

Studies were included if they were randomised controlled trials (RCTs), randomised or non-randomised crossover studies, cohort studies, case series, or animal studies (only used to identify adverse effects of suctioning; not used in the development of recommendations).

\section{Data extraction}

Data were extracted on study type and date, allocation methods, patient inclusion and exclusion criteria, adequacy of follow up, comparison of baseline characteristics, specific interventions, outcome measures, and results. No formal tool was used to assess quality of individual studies.

\section{Main results}

161 RCTs, non-randomised controlled trials, randomised or non-randomised crossover studies, and cohort studies were included. Meta-analysis was not done because of differences among studies. Selected results of RCTs and randomised crossover studies of adult patients are summarised in the table.

\section{Conclusion}

Several techniques have beneficial effects during suctioning of ventilated and intubated patients.

\section{COMMENTARY}

Suctioning intubated patients aids in removing secretions and maintaining a patent airway, while promoting optimal ventilation and oxygenation. The development of guidelines by Brooks et al supports clinical decision making by taking into consideration both the benefits and complications associated with the procedure. Recommendations for preoxygenation, hyperoxygenation, hyperinflation plus method of delivery, swivel adaptor use, and others were reported.

The authors noted that insufficient evidence exists regarding several aspects of suctioning. For example, instillation of normal saline is thought to thin and loosen secretions, lubricate the suction catheter, and stimulate coughing. ${ }^{1}$ However, normal saline instillation may also cause a decrease in oxygen saturation ${ }^{2}$ and dislodge more bacteria in endotracheal tubes than use of suction catheters alone. ${ }^{3}$ Brooks $e t$ al highlight the paucity of scientific evidence to support saline instillation.

Subsequent guidelines need to address the evidence for the heated humidification of the inspired gas, monitoring of patient hydration status, and use of mucolytic agents or nebulisers. Patients receiving $100 \%$ humidity heated to core temperature $\left(37^{\circ} \mathrm{C}\right)$ are reported to be at the optimal level for mucosal function, maximising mucous clearance. ${ }^{4}$

Brooks et al provide recommendations useful to healthcare providers engaged in the care of ventilated and intubated patients. These guidelines for suctioning can be applied to all ventilated patients, including those who are on volume control, synchronised intermittent mandatory ventilation, or pressure support. However, guidelines do not pre-empt sound clinical decision making. Clinicians still need to pay close attention to patient oxygenation levels, haemodynamic status, and responses to suctioning, especially if patients are unstable or have thick and tenacious secretions.

Ruth Taylor-Piliae, RN, CNS, MN Doctoral Student, School of Nursing University of California, San Francisco San Francisco, California, USA

1 Blackwood B. Normal saline instillation with endotracheal suctioning: primum non nocere (first do no harm). J Adv Nurs 1999;29:928-34.

2 Ackerman MH. The effect of saline lavage prior to suctioning. AmJ Crit Care 1993;2:326-30.

3 Hagler DA, Traver GA. Endotracheal saline and suction catheters: sources of lower airway contamination. Am J Crit Care 1994;3:444-7.

4 Williams R, Rankin N, Smith T, et al. Relationship between the humidity and temperature of inspired gas and the function of the airway mucosa. Crit Care Med 1996;24:1920-9.

Effectiveness of selected techniques during suctioning (randomised controlled trials only)

\begin{tabular}{|c|c|}
\hline Technique & Results (number of trials, number of patients) \\
\hline Preoxygenation & Improved arterial oxygen saturation $\left(\mathrm{SaO}_{2}\right)(2$ trials, $\mathrm{n}=12$ and $\mathrm{n}=17)$ \\
\hline Hyperoxygenation & Maintained $\mathrm{O}_{2}$ levels in mechanically ventilated patients (4 trials, $\left.\mathrm{n}=10-24\right)$ \\
\hline Hyperoxygenation + hyperinflation & Added value of hyperinflation unclear in mechanically ventilated patients ( 4 trials, $n=10-24$ ) \\
\hline Double lumen insufflation catheters & Maintained $\mathrm{O}_{2}$ levels throughout suctioning at flow rates of $10-15 \mathrm{I} / \mathrm{min}(4$ of 5 trials, $\mathrm{n}=10-38)$ \\
\hline Hyperinflation alone & $\begin{array}{l}\left.\text { Unclear benefits on } \mathrm{O}_{2} \text { levels after cardiac surgery; increase in blood pressure ( } 4 \text { trials, } n=8-34\right) \text {. Increase in volume } \\
\text { may result in increased intracranial pressure in patients with head injury ( } 2 \text { trials, } n=10-37)\end{array}$ \\
\hline $\begin{array}{l}\text { Oxygenation using a manual resuscitation } \\
\text { bag } \vee \text { ventilator }\end{array}$ & Ventilators were more effective for oxygen delivery (greater increases in $\left.\mathrm{PAO}_{2}\right)(3$ of 4 trials, $\mathrm{n}=10-33$ ) \\
\hline Open v closed suctioning systems & $\begin{array}{l}\text { No difference for nosocomial pneumonia ( } 3 \text { trials, } \mathrm{n}=20-84 \text {, all had insufficient power) or mortality ( } 1 \text { trial, } \mathrm{n}=84) \text {. } \\
\text { Greater decrease in } \mathrm{PaO}_{2} \text { ( } 1 \text { trial, } \mathrm{n}=8 \text {, not clinically significant) }\end{array}$ \\
\hline Saline instillation & $\begin{array}{l}\text { No difference for oxygenation, gas exchange, heart rate, or blood pressure in ventilated and non-ventilated patients } \\
\text { with tracheostomies ( } 5 \text { trials, } n=15-45)\end{array}$ \\
\hline
\end{tabular}

